\title{
Moral uncertainty and the moral status of early human life
}

\author{
Michael J. Selgelid \\ Centre for Human Bioethics, Monash University \\ michael.selgelid@monash.edu
}

In a recent article titled 'After-Birth Abortion: Why Should the Baby Live?', Alberto Giubilini and Francesca Minerva argue that it may be morally permissible to kill a newborn baby, unwanted by the parents, even if it is healthy. ${ }^{1}$ In any case where abortion would be acceptable, they argue, what they call 'after-birth abortion' - i.e. termination of a newborn baby - should be permissible too. Their point is that the moral status of a human life does not change when the being in question moves from inside to outside the womb. Because a newborn baby (like a late-term fetus) lacks aims, according to these authors, the aims of parents should determine whether or not a baby should live.

One might object to their conclusion by pointing to the fact that there are presumably very many people in the world who have strong preferences that newborn healthy babies are never killed (whether or not they are wanted by their parents). Giubilini and Minerva assume that (a) newborn babies do not have aims and therefore lack the moral status of persons and (b) the aims of actual persons should determine whether or not babies should live. Even if (a) and (b) are correct, it is questionable whether or not, or why, the aims of parents (who might want their baby killed) should be thought to outweigh the aims of others who are strongly opposed to baby-killing. This raises questions about how the aims of various people should be assessed and weighed against one another in cases of conflict. While Giubilini and Minerva appear to adopt a form of preference utilitarianism, it is by no

1 Alberto Giubilini and Francesca Minerva. 'After-birth abortion: why should the baby live?', Journal of Medical Ethics. Accessed 25 April 2012. Available from: http://jme.bmj. com/content/early/2012/03/01/medethics-2011-100411.full 
means obvious that (aggregate) preference satisfaction would be maximised by a practice involving 'after-birth abortion' of newborn babies unwanted by their parents (even if it is safe to assume that such babies lack aims and/or the moral status of persons).

In any case, their argument invites reconsideration of questions regarding the moral status of early human lives. In what follows, I will argue that there are multiple conflicting plausible (or, at least, possibly true) views about the moral status of the embryo, fetus, and newborn baby - and that the moral status of such beings is ultimately uncertain. If this is correct, then the killing of such beings would be morally problematic - because it would run the risk of killing beings with significant moral status. I will conclude that it is appropriate for states, in particular, to adopt the perspective according to which the moral status of early human lives is uncertain - and that this should commit them to a 'gradualist' position, according to which the protections due to early human lives is a function of their stage of development.

Giubilini and Minerva appeal to an idea about the moral status of newborn babies that has been advocated by other philosophers for decades. Michael Tooley, for example, famously argued that newborn babies are not persons with a right to life in his 1972 article 'Abortion and Infanticide'. Tooley argues that ' $[a] n$ organism possesses a serious right to life only if it possesses the concept of a self as a continuing subject of experiences and other mental states, and believes that it is itself such a continuing entity.' ${ }^{2}$ His point is that to have a right to something, one must be able to desire that thing - and to desire something one must have a concept of it. Because a newborn baby does not have sufficiently complex psychological capacities to have a concept of continuation of (its) life, it cannot desire continuation of (its) life, and thus cannot have a right to it. Or so the argument goes. A similar position has been advocated by Helga Kuhse and Peter Singer. ${ }^{3}$

2 Michael Tooley, 'Abortion and infanticide', Philosophy and Public Affairs 2 (1), Autumn 1972, 37-65.

3 Helga Kuhse and Peter Singer, Should the Baby Live, Oxford, UK: Oxford University Press, 1985; Peter Singer, Rethinking Life and Death, Melbourne: The Text Publishing Company, 1994. 
Key assumptions of Tooley are that (1) being able to desire something is a necessary condition of having a right to it and (2) having a concept of something is a necessary condition of being able to desire it. I am willing to grant that these are plausible assumptions, and that the conclusions he draws from them are likewise plausible. Having granted this, however, I would suggest that these premises, despite their plausibility, are at least open to question - i.e. these are things that there can presumably be reasonable disagreement about. It should likewise be noted that (1) and (2) are largely asserted rather than argued for by Tooley. I would guess that many (if not most) people have stronger intuitions about the wrongness of killing babies than they have about the truth of (1) and (2).

Let's consider a possible counterexample to Tooley's position. Imagine that my uncle (the astronaut) discovered (and rightfully came to own) a very strange, complicated, and wonderful thing during his explorations in outer space - and that he left it to me in his will. When he dies, we might reasonably think that I would then have a right to possession of this thing. Because it is so strange - i.e. so unlike anything I have ever experienced before - let's imagine that I'm unable to have a concept of it. (We might even imagine that the thing is so complex that it is beyond my comprehension.) According to the view put forward by Tooley, I would then be unable to desire it and thus lack a right to it. The point of this and other possible counterexamples is not to show that Tooley's premises are certainly false. My purpose here is merely to suggest that they might be false - and that his argument for the moral permissibility of infanticide might, therefore, not be sound.

Whether or not (1) and (2) are false, furthermore, one might doubt Tooley's claims that newborn babies do not actually have the concepts and desires he takes to be necessary for a right to life. Perhaps they at least have the concepts/ desires in question (and thus a right to life) to a degree?

At one end of the spectrum, liberals like Tooley deny that newborn babies possess a right to life. At the other end of the spectrum, many Catholics argue that even very early embryos are persons with a right to life. Such beliefs are often based upon the idea that embryos are ensouled very early in their development. If early embryos do in fact have souls, this might be a good reason 
for thinking that they have a right to life. While I do not personally subscribe to the religious views under consideration, I am happy to grant that they just might be true. Where is - and what would be - proof that they are false? (Ensoulment would be an amazing thing if it occurs - but it is also amazing that there is something rather than nothing, and that life itself exists. That something would be amazing is not reason for denying its truth and/or possibility. The world is a mysterious place.) If such views (regarding ensoulment) are in fact true, then the killing of embryos, fetuses, and newborn babies would arguably involve murder. From a secular perspective one might question how much weight we should give to the (perhaps merely theoretical) possibility that early embryos and fetuses possess souls - and one might argue that we should not give much weight to such a possibility in the absence of positive evidence. On the other hand, however, many people claim that positive evidence exists (and is revealed via sacred texts and so on). This leads to questions about what should count as good standards of evidence - and this, again, is something there might be reasonable disagreement about. ${ }^{4}$

Between the extremes is a more moderate view - and one that might be most in line with ordinary secular thinking. From a commonsense secular perspective, one might think that (1) early embryos are just tiny clusters of cells that lack much (if any) moral status at all and (2) that newborn babies possess the full rights and/or value attributed to ordinary children and adults. ${ }^{5}$ One good way of making sense of this position would be to think that the process of development from embryo to baby involves a gradual accumulation of the rights (and value) attributed to ordinary people. According to this kind of position, we might think that a mid-term fetus, for example, has a right to life to a certain degree (rather than thinking that such rights are possessed or not in an either-or fashion). As with the liberal and Catholic positions considered above, I would posit that this kind of picture is at least possibly true, if not highly

4 H. Tristram Engelhardt Jr., The Foundations of Bioethics, Second Edition, New York: Oxford University Press, 1996

5 An alternative moderate position might hold that newborn babies have a right to life and/or value to a significant degree (though perhaps not the full right to life and/or value attributed to prototypical persons). 
plausible. (The intuitive plausibility of this kind of position provides further grounds for challenging the argument put forward by Tooley.)

If I am correct that the three kinds of positions I have briefly sketched above are at least possibly true, then the moral status of early human beings (e.g. until just after birth) is ultimately uncertain. It is possible, for example, that a fetus just prior to birth (1) has no right to life, (2) has a right to life to a highly significant degree, but not quite the full right to life attributed to ordinary people, and (3) has a full right to life. I do not personally believe that science, logic, or philosophy can conclusively demonstrate the truth or falsity of any one of these positions. If the moral status of early human lives is ultimately uncertain, then practices that involve the killing of embryos, fetuses, and newborn babies is morally problematic - because such practices involve the killing of beings that just might have significant, if not full, moral status. ${ }^{6}$ The killing of such beings would thus involve moral risk-taking. This would not mean that killing such beings would always be wrong and/or should be forbidden. It would mean, however, that one would need to have a good reason for taking the risks in question.

Though not often explicitly stated as such, the perspective according to which the moral status of the fetus is uncertain makes sense of common views about the morality of abortion in particular. ${ }^{7}$ It is commonly thought that abortion is most permissible in cases involving pregnancy due to rape, pregnancy that threatens the health of the mother, pregnancy expected to result in severely diseased offspring, and pregnancy in cases where no child is wanted. Most people nonetheless presumably think that abortion for relatively trivial reasons (e.g. in order to conceive again with the hope of having a boy rather than a girl) would be wrong.

If there should be separation of church and state - and if the three kinds of positions outlined above amount to what are ultimately differences in religious outlook - then the moral uncertainty perspective regarding the moral status of early human life is especially appropriate for adoption by governments.

6 Michael J. Selgelid, 'Eugenic abortion, moral uncertainty, and social consequences', Monash Bioethics Review 20 (2), April 2001, 26-42.

7 Ibid. 
Governments (committed to separation of church and state), that is, should take plausible and/or possibly true religious views into account without adopting or denying any religious view ${ }^{8}$ in particular. An interesting implication of this is that - without actually adopting the gradualist position as true - governments should grant protection to early human lives in proportion to their stage of development. Because what I have called the moderate view above is plausible, there is a plausible reason for thinking that later stage fetuses have more moral status than early stage fetuses. There is presumably no plausible reason, however, for thinking that early stage fetuses have more moral status than later stage fetuses. Other things being equal, if there are more plausible reasons for thinking that one being (i.e. a later stage fetus) has more moral status than another (i.e. an early stage fetus), then a government (involving separation of church and state) should presumably grant more protection to the former. Unfortunately, for now, this leaves open the question of just how much protection a government should grant a fetus at any particular stage of development.

In any case, the idea that governments should take a gradualist position with regard to protection of fetuses is in line with common practice insofar as abortion of very late stage (i.e. third trimester) fetuses is commonly prohibited in jurisdictions tolerant of abortion at earlier stages (i.e. first and second trimester). It is noteworthy that, though they argue that 'after-birth abortion' should be permitted in any cases where abortion is considered permissible, Giubilini and Minerva fail to mention that abortion of fully developed fetuses (pre-birth) is often, if not usually, itself considered impermissible.

8 I am here using the expression 'religious view' broadly - i.e. to refer to outlooks that require leap of faith about debatable matters (whether or not belief in the existence of God is involved). 